\title{
Cerebrospinal fluid neurohypophysial peptides in benign intracranial hypertension
}

\author{
JONATHAN SECKL, STAFFORD LIGHTMAN
}

From the Department of Medicine, Charing Cross and Westminster Medical School, Westminster Hospital, London UK.

SUMMARY The cerebrospinal fluid (CSF) concentrations of arginine vasopressin (AVP) and oxytocin (OT) were investigated both in patients with benign intracranial hypertension and in age and sex matched controls. Twenty eight lumbar punctures were performed on 15 patients with benign intracranial hypertension as part of their routine investigation and therapy. All patients had raised intracranial pressure $(27 \cdot 4, \mathrm{SE} 1.7 \mathrm{~cm} . \mathrm{CSF})$. CSF AVP levels were significantly elevated in benign intracranial hypertension $(2 \cdot 1, \mathrm{SE} 0.3 \mathrm{pmol} / \mathrm{l})$ compared with controls $(0.7, \mathrm{SE} 0.1 \mathrm{pmol} / 1$, $\mathrm{p}<0.001$ ) but CSF OT concentrations were similar in both groups. CSF osmolality and plasma AVP and osmolality were identical in patients and controls. There was no correlation between CSF AVP concentration and intracranial pressure. The selective elevation of AVP in CSF may be of importance in the pathogenesis of raised intracranial pressure in benign intracranial hypertension.

Arginine vasopressin (AVP) and oxytocin (OT) are widely distributed in the CNS, not only in the hypothalamus, but also in various extrahypothalamic regions and the spinal cord.$^{1-3}$ Both peptides have also been demonstrated in CSF by bioassay and radioimmunoassay techniques. ${ }^{45}$ The blood-brain barrier prevents access of circulating AVP and OT to the CSF. ${ }^{5}$ In addition, the classical physiological stimuli to neurohypophysial peptide secretion do not result in marked alterations of CSF concentrations of OT or AVP, suggesting that the CSF peptides have distinct origins and regulation from the hypothalamoneurohypophysial system. The functions of these hormones in the brain and CSF are unknown.

There is accumulating evidence for an association between elevated CSF AVP concentrations and disorders associated with raised intracranial pressure (ICP) including benign intracranial hypertension, ${ }^{6-9}$ subarachnoid haemorrhage ${ }^{10}$ and meningitis. ${ }^{11}$ It is not known whether the rise in CSF AVP is part of the primary pathology or simply a non-specific response to changes in ICP.

We have recently demonstrated ${ }^{12}$ that intracerebroventricular infusion of AVP in the cons-

Address for reprint requests: Dr J R Seckl, University of Edinburgh, Department of Medicine, Western General Hospital, Edinburgh, EH4 2XU, UK.

Received 30 October 1987 and in final revised form 21 July 1988. Accepted 21 July 1988 cious goat leads to elevation of ICP by a mechanism independent of any effect on systemic arterial blood pressure or circulating AVP. We have therefore investigated CSF neurohypophysial peptide concentrations in patients with benign intracranial hypertension and controls.

\section{Methods}

Fifteen patients with benign intracranial hypertension (mean age 35.5y, range 14-55y; 13F:2M) were investigated (table 1).

Table 1 Clinical characteristics, CT and CSF findings at presentation of patients with benign intracranial hypertension.

\begin{tabular}{|c|c|c|c|c|c|c|}
\hline Sex & Age & $\begin{array}{l}\text { Duration } \\
\text { of } \\
\text { symptoms }\end{array}$ & $C T$ & $\begin{array}{l}\text { Protein } \\
(\mathrm{g} / \mathrm{l})\end{array}$ & $\begin{array}{l}W B C \\
\left(10^{6} / l\right)\end{array}$ & $\begin{array}{l}\text { ICP } \\
(\mathrm{cm} . \mathrm{CSF})\end{array}$ \\
\hline $\begin{array}{l}\mathbf{F} \\
\mathbf{F} \\
\mathbf{F} \\
\mathbf{M} \\
\mathbf{F} \\
\mathbf{F} \\
\mathbf{F} \\
\mathbf{F} \\
\mathbf{F} \\
\mathbf{F} \\
\mathbf{M} \\
\mathbf{F} \\
\mathbf{F} \\
\mathbf{F} \\
\mathbf{F}\end{array}$ & $\begin{array}{l}35 \\
35 \\
53 \\
45 \\
28 \\
25 \\
32 \\
55 \\
50 \\
26 \\
28 \\
21 \\
48 \\
37 \\
14\end{array}$ & $\begin{array}{l}2 y \\
5 y \\
5 y \\
2 y \\
1 y \\
4 m \\
5 y \\
3 m \\
1 y \\
5 m \\
1 m \\
1 y \\
1 y \\
1 y \\
1 \mathrm{~m}\end{array}$ & $\begin{array}{l}\mathbf{N} \\
\mathbf{N} \\
\mathbf{N} \\
\mathbf{N} \\
\mathbf{N} \\
\mathbf{N} \\
\mathbf{N} \\
\mathbf{E S} / \mathbf{V} \\
\mathbf{N} \\
\mathbf{N} \\
\mathbf{N} \\
\mathbf{E S} \\
\mathbf{N} \\
\mathbf{N} \\
\mathbf{N}\end{array}$ & $\begin{array}{l}0.65 \\
0.42 \\
0.68 \\
0.53 \\
0.32 \\
0.41 \\
0.38 \\
0.55 \\
0.53 \\
0.57 \\
0.69 \\
0.30 \\
0.42 \\
0.47 \\
0.14\end{array}$ & $\begin{array}{r}<3 \\
<3 \\
<3 \\
<3 \\
<3 \\
<3 \\
11 \\
<3 \\
<3 \\
\quad 9 \\
<3 \\
<3 \\
<3 \\
<3 \\
<3\end{array}$ & $\begin{array}{l}27 \\
26 \\
30 \\
28 \\
37 \\
41 \\
30 \\
26 \\
28 \\
33 \\
40 \\
20 \\
32 \\
42 \\
33\end{array}$ \\
\hline
\end{tabular}

$\mathbf{N}=$ Normal, $\mathbf{V}=$ small ventricles, $\mathrm{ES}=$ empty sella on $\mathrm{CT}$. 
All gave their informed consent to the study which had been approved by the local ethical committee. All had papilloedema and enlarged blind spots. Ventricular size was normal or symmetrically decreased on computed tomography (CT); two also showed empty sellae, a feature associated with elevated intracranial pressure (table 1). Ten patients were on no medication prior to study, one was receiving paracetamol for headaches, one was taking diuretics and three were taking acetazolamide. One patient on acetazolamide was receiving chronic lithium carbonate therapy for manic depressive disease.

CSF was obtained at routine lumbar puncture (LP), which was performed between 09:00 and 12:00h, under local anaesthesia. Some patients were investigated more than once (total of 28 LPs). Patients were positioned recumbent for 30 min prior to LP. A blood sample was taken and then LP was performed in the lateral decubitus position. Intracranial pressure was estimated by direct manometry before samples were obtained for routine biochemistry, microscopy and peptide and osmolality estimation. Serial $5 \mathrm{ml}$ aliquots of CSF were obtained from 13 patients.

The controls (mean age $35 \cdot 5 \mathrm{y}$, range $18-61 \mathrm{y} ; 10 \mathrm{~F}: 6 \mathrm{M}$ ) comprised 16 patients undergoing LP as part of the routine investigation of lumbar disc disease (8), headache (3), possible multiple sclerosis (3), acute myeloid leukaemia without CNS involvement (1) and benign cerebral calcification (1). Paired blood and CF samples were obtained after 30 min recumbency and treated similarly to samples from benign intracranial hypertension patients.

\section{Analyses}

Venous blood was collected into lithium heparin tubes on ice, centrifuged at $4^{\circ} \mathrm{C}$, the plasma separated, an aliquot retained for osmolality estimation by freezing point depression, and the remainder stored at $-20^{\circ} \mathrm{C}$ for subsequent peptide radioimmunoassay. CSF was stored at $-20^{\circ} \mathrm{C}$. Plasma was extracted through octadecasilyl silica cartridges (Sep-pak C18, Waters Associates, Milford, MA) prior to peptide estimation by sensitive and specific radioimmunoassays. ${ }^{13}$ Extraction yield was $>90 \%$ for both OT and AVP; no correction for yield was made. CSF peptides were estimated directly. Intraassay coefficient of variation was $<5 \%$ for both OT and AVP ((2 fmol standard, 10 replicates). Interassay coefficients of variation were $10 \%$ for OT and $15 \%$ for AVP ( 2 fmol standard). Minimum detectable concentrations, under the assay conditions employed, were $0.25 \mathrm{pmol} / 1$ for AVP in CSF and plasma, and $2 \mathrm{pmol} / 1$ for CSF OT. High performance liquid chromatography (HPLC) was performed on a reverse phase column (Nucleosil C8, Macherey-Nagel, Duren) using a linear gradient of $12-48 \%$ acetonitrile against $0.1 \%$ trifluoroacetic acid. Fractions of CSF from two patients with benign intracranial hypertension were assayed, as above, for AVP and compared with authentic, synthetic standard AVP (Cambridge Research Biochemicals, Cambridge).

\section{Statistics}

CSF peptides were not normally distributed and were compared by the Wilcoxon signed rank test. Other comparisons were made using Student's $t$ test. Linear regression analysis was performed by the least squares method. Statistical significance was set at $p<0.05$. Values are means, $S E$.
Results

Intracranial pressure was significantly $(p<0.001)$ elevated in patients with benign intracranial hypertension (27.4, SE $1.5 \mathrm{~cm} . \mathrm{CSF})$ compared with controls (13.6, SE $1.7 \mathrm{~cm} . \mathrm{CSF})$. CSF protein concentration $(0.47, \mathrm{SE} 0.04 \mathrm{~g} / \mathrm{l}$ in benign intracranial hypertension, $0.48, \mathrm{SE} 0.07 \mathrm{~g} / \mathrm{l}$ in controls) and CSF cell counts were similar in both groups.

CSF AVP concentration was $2 \cdot 1$, SE $0.3 \mathrm{pmol} / 1$ in benign intracranial hypertension patients, significantly greater than controls $(0 \cdot 7$, SE $0.1 \mathrm{pmol} / 1$, $\mathrm{p}<0.001)$. CSF OT levels however, were similar in patients $(9 \cdot 3$, SE $1 \cdot 1 \mathrm{pmol} / \mathrm{l})$ and controls $(8 \cdot 8, \mathrm{SE}$ $1.4 \mathrm{pmol} / \mathrm{l})$. Examination of the data (fig) revealed a single control CSF OT value considerably higher than the rest. Exclusion of this point reduced mean (but not median) control CSF OT to $7.8 \mathrm{SE} 0.9 \mathrm{pmol} / 1$, but this adjusted control value was also not significantly lower than CSF OT in benign intracranial hypertension patients $(p=0.49)$.

Plasma AVP and osmolality and CSF osmolality were identical in both patients and controls, (table 2). There were no significant differences between the CSF AVP concentrations in the first $(2 \cdot 1, \mathrm{SE} 0.2 \mathrm{pmol} / \mathrm{l})$ and the last $(1 \cdot 7, \mathrm{SE} 0.2 \mathrm{pmol} / \mathrm{l})$ aliquots of CSF, nor were there differences between the initial $(8.9$, SE $1.7 \mathrm{pmol} / \mathrm{l})$ and final (8.9, SE $1.3 \mathrm{pmol} / \mathrm{l})$ CSF OT levels. There was no correlation between CSF AVP and intracranial pressure in either patients $(r=-0.2)$, controls, or combined patients and controls $(r=0 \cdot 1)$.

HPLC analysis of CSF from patients with benign
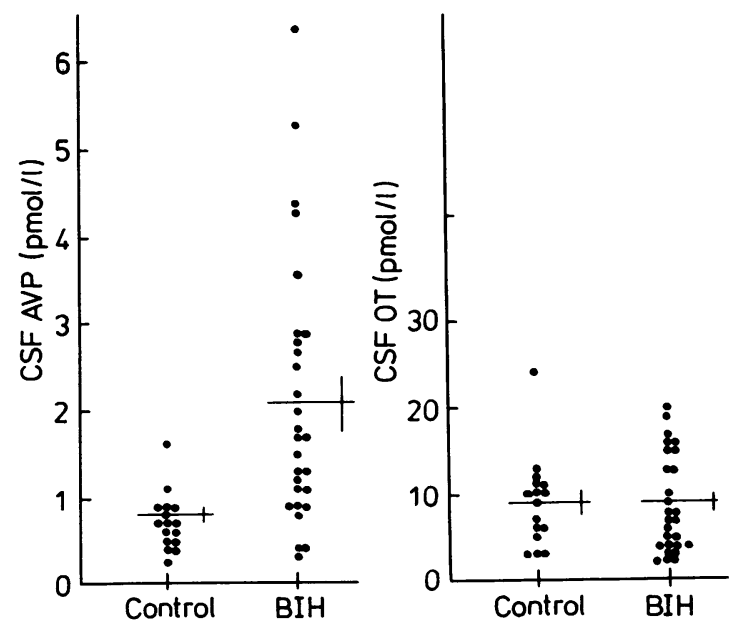

Figure CSF vasopressin ( $A V P$ ) and oxytocin (OT) concentrations in patients with benign intracranial hypertension (BIH) and controls. 
Table 2 Comparison of plasma and cerebrospinal fluid $(C S F)$ data in patients with benign intracranial hypertension (BIH) and controls.

\begin{tabular}{lcc}
\hline & BIH & Controls \\
\hline ICP (cm.CSF) & $27 \cdot 4$, SE 1.5 & $13 \cdot 6$, SE 1.7 \\
Plasma AVP (pmol/l) & $1 \cdot 8$, SE 0.5 & $1 \cdot 3$, SE 0.5 \\
CSF OSMOL (mOsm/kg) & 288, SE 2 & 288, SE 2 \\
Plasma OSMOL (mOsm/kg) & 288, SE 2 & 290, SE 1 \\
\hline
\end{tabular}

ICP = intracranial pressure.

intracranial hypertension confirmed that AVP immunoreactivity eluted in the same position as authentic synthetic AVP.

\section{Discussion}

All patients investigated had elevated intracranial pressure without focal abnormality on CT scan, Although benign intracranial hypertension is likely to be a heterogenous disorder, the patients described here were similar in characteristics and clinical findings to those reported by others. ${ }^{6-9}$ There was no evidence of abnormalities of CSF protein concentration, cell count or type.

Previous studies have demonstrated raised levels of CSF AVP in patients with benign intracranial hypertension and other disorders associated with raised ICP, though there was considerable overlap with control subjects in some series. ${ }^{9}$ Our results showed a three-fold elevation of CSF AVP in patients with benign intracranial hypertension. Again there was overlap in CSF AVP values between some benign intracranial hypertension patients and controls. In addition, we were unable to demonstrate a direct relationship between CSF AVP concentration and intracranial pressure, in contrast to previous results. ${ }^{8}$ These discrepancies might suggest that the CSF AVP elevation observed represents a secondary epiphenomenon.

On the other hand, CSF OT was identical in patients and controls, suggesting that the elevation of CSF AVP in benign intracranial hypertension does not represent a non-specific release of peptides secondary to the pathological process. OT is a particularly good control for AVP in view of its similar structure and distribution throughout the CNS. ${ }^{314}$ The elevation of AVP, but not OT, in CSF is unlikely to reflect differences in the clearance rates of these similar nonapeptides. $^{5}$ In addition, the HPLC analysis provides strong evidence that the immunoreactivity measured is authentic AVP rather than any accumulating metabolic product or cross-reacting substance present in the CSF in benign intracranial hypertension. Furthermore, the overlap of values between benign intracranial hypertension and con- trols does not exclude a primary role for CSF AVP in the pathogenesis of raised ICP. Indeed, this variability should perhaps be of no surprise in a condition of long duration and fluctuating severity. It is unlikely that the peptide would act directly in the CSF itself, raised levels presumably represent dilution of AVP released from sites of action within the CNS or related structures.

Although early work on the effects of AVP on ICP in anaesthetised rabbits yielded conflicting results, ${ }^{9}$ we have recently demonstrated that intracerebroventricular infusion of AVP leads to elevation of ICP in conscious goats. ${ }^{12}$ There are several possible mechanisms by which elevations of AVP in CSF might affect ICP. AVP injections into both the CSF and brain stem have been shown to alter cardiovascular parameters. ${ }^{1617}$ However, in the conscious goat, systemic blood pressure changes were not an important factor in the elevation of ICP observed. ${ }^{12}$

Central injection of AVP in nanomolar doses has been shown to alter brain capillary permeability ${ }^{18}$ and increase cerebral hydration in experimental animals. ${ }^{19}{ }^{20}$ Although increased cerebral hydration is seen in intracranial infections, such as meningitis, cerebral oedema is not usually reported in benign intracranial hypertension. ${ }^{21}$ Indeed, in benign intracranial hypertension there is considerable evidence for altered CSF dynamics; most suggests increased resistance to absorption of CSF, ${ }^{21-23}$ although some studies have proposed excessive CSF formation. ${ }^{624}$ Furthermore, we have recently demonstrated that elevation of CSF AVP in the goat leads to a fall of CSF absorption rate without significant? alteration of CSF formation rate. ${ }^{25}$ These changes in CSF dynamics would be fully in accord with the normal CT scan findings in this condition. ${ }^{26}$

Intracerebroventricular infusion of AVP in anaesthetised dogs is associated with a reduction in circulating AVP levels. ${ }^{27}$ This might be expected to affect CSF formation rate by a direct action on the choroid plexus, ${ }^{2829}$ but in the conscious goat plasma AVP concentrations were not significantly altered by intracerebroventricular AVP infusion. ${ }^{12}$ These differences may represent interspecific differences or the differential effects of anaesthetic agents, ${ }^{30}$ which may themselves alter CSF dynamics and intracranial pressure. ${ }^{31}$ In our patients with benign intracranial hypertension plasma AVP concentrations were similar to controls, suggesting that peripheral hormonal effects are not important in the pathogenesis of the intracranial hypertension observed.

We thank Professor W I McDonald of the National Hospital for Nervous Diseases, Maida Vale and our colleagues at the National Hospitals for Nervous Diseases, Queen Square for permission to investigate 
their patients. Molly Seckl provided invaluable secretarial assistance. JRS was in receipt of a Jules Thorn Charitable Trust Fellowship.

\section{References}

1 Sofroniew MV. Projections from vasopressin, oxytocin and neurophysin neurons to neural targets in the rat and human. $J$ Histochem Cytochem 1980;28:475-8.

2 Buijs RM, Swaab DF, Dogterom J, van Leeuwen FW. Intra- and extrahypothalamic vasopressin and oxytocin pathways in the rat. Cell Tissue Res 1978;186:423-33.

3 Jenkins JS, Hawthorn AJ, Rossor MN. Quantitative distribution of neurohypophysial hormones in human brain and spinal cord. In: BA Cross, G Leng, eds. The Neurohypophysis: Structure, Function and Control. Amsterdam: Elsevier, 1985;123-8.

4 Jenkins JS, Mather HM, Ang V. Vasopressin in human cerebrospinal fluid. J Clin Endocrin Metab 1980:50:364-7.

5 Robbins ICAF. Neurohypophysial peptides in cerebrospinal fluid. In: BA Cross, G Leng, eds. The Neurohypophysis: Structure, Function and Control. Amsterdam: Elsevier 1983:129-55.

6 Hammer M, Sorensen PS, Gjerris F, Larsen K. Vasopressin in the cerebrospnal fluid of patients with normal pressure hydrocephalus and benign intracranial hypertension. Acta Endocrinol 1982;100:211-5.

7 Sorensen PS, Gjerris F, Hamer M. Cerebrospinal fluid vasopressin in neurological and psychiatric disorders. J Neurol Neurosurg Psychiatry 1985;48:50-57.

8 Sorensen PS, Gjerris F, Hammer M. Cerebrospinal fluid vasopressin and increased intracranial pressure. Ann Neurol 1984;15:435-40.

9 Reid AC, Morton JJ. Arginine vasopressin levels in cerebrospinal fluid in neurological disease. J Neurol Sci 1982;54:295-301.

10 Mather HM, Ang V, Jenkins JS. Vasopressin in plasma and CSF of patients with subarachnoid haemorrhage. J Neurol Neurosurg Psychiatry 1981;44:216-9.

11 Garcia H, Kaplan SL, Feigin RD. Cerebrospinal fluid concentration of arginine vasopressin in children with bacterial meningitis. J Pediatr 1981;98:67-70.

12 Seckl JR, Lightman SL. Intracerebroventricular arginine vasopressin causes intracranial pressure to rise in conscious goats. Brain Res 1987;423:279-85.

13 Seckl JR, Williams TDM, Lightman SL. Oral hypertonic saline causes transient fall of vasopressin in humans. Am J Physiol 1986;251:R214-R217.

14 Rossor MN, Iversen LL, Hawthorn J, Ang VTY, Jenkins JS. Extrahypothalamic vasopressin in human brain. Brain Res 1981;214:349-55.

15 Noto T, Nakajima T, Saki Y, Nagawa Y. Effect of vasopressin on intracranial pressure of rabbit. Endocrinol Japon 1978;25: $5991-6$.
16 Pittman QJ, Lawrence D, McLean L. Central effects of arginine vasopressin on blood pressure in rats. Endocrinology 1982;110:1058-60.

17 Vallejo M, Carter DA, Lightman SL. Haemodynamic effects of arginine vasopressin microinjections into the nucleus tractus solitarius: a comparative study of vasopressin, a selective vasopressin receptor agonist and antagonist, and oxytocin Neurosci Lett 1984;52:247-52.

18 Raichle ME, Grubb RL. Regulation of brain water permeability by centrally-released vasopressin. Brain Res 1978;143:191-4.

19 Doczi T, Szerdahelyi P, Gulya K, Kiss J. Brain water accumulation after the central administration of vasopressin. Neurosurgery 1982;11:402-7.

20 Doczi T, Laszio FA, Szerdahelyi P, Joo F. Involvement of vasopressin in brain edema formation: further evidence obtained from the Brattleboro diabetes insipidus rat with experimental subarachnoid hemorrhage. Neurosurgery $1984 ; 14: 436-41$.

21 Janny P, Chazal J, Colnet G, Irthum B, Georget A-M. Benign intracranial hypertension and disorders of CSF absorption. Surg Neurol 1981;15:168-74.

22 Johnston I. Reduced CSF absorption syndrome. Reappraisal of benign intracranial hypertension and related conditions. Lancet 1973;ii:418-21.

23 Martins AN. Resistance to drainage of cerebrospinal fluid: clinical measurement and significance. J Neurol Neurosurg Psychiatry 1973;36:313-8.

24 Donaldson JO. Pathogenesis of pseudotumour cerebri syndromes. Neurology 1981;31:877-80.

25 Lightman SL, Seckl JR. Effect of intracerebroventricular vasopressin on cerebrospinal fluid dynamics in the conscious goat. J Physiol (Lond) 1988;399:47P.

26 Hakim S, Venegas JB, Burton JD. The physics of the cranial cavity, hydrocephalus and normal pressure hydrocephalus: mechanical interpretation and mathematical model. Surg Neurol 1976;5:187-210.

27 Wang BC, Share L, Crofton JT. Central infusion of vasopressin decreased plasma vasopressin concentration in dogs. Am J Physiol 1982;243:E365-E369.

28 Davson H, Segal MB. The effects of some inhibitors and accelerators of sodium transport on the turnover of ${ }^{22} \mathrm{Na}$ in the cerebrospinal fluid and the brain. J Physiol (Lond) 1970;209:131-53.

29 Schultz WJ, Brownfield MS, Kozlowski GP. The hyothalamochoroidal tract. II. Ultrastructural response of the choroid plexus to vasopressin. Cell Tissue Res 1977;178:129-41.

30 Correa FMA, Magro IAS, Peres-Polon VL, Antunes-Rodriguez J. Mechanism of the CNS-mediated pressor response to intracerebroventricular injection of noradrenaline in unanaesthetised rats. Neuropharmacol 1985;24:831-7.

31 Artru AA. Effects of halothane and fentanyl anesthesia on resistance to reabsorption of CSF. J Neurosurg 1984;60:252-6. 